\title{
Botanical Knowledge of a Group of College Students in South Carolina, U.S.A.
}

\author{
Gail E. Wagner
}

\section{Education}

\begin{abstract}
Thirty-one 18-22-year-old college students in South Carolina, U.S.A., were asked to freelist garden flowers, local grasses, local crops, and native/local trees, vines, and wildflowers/weeds. Answers were scored as correct, wrong, or inappropriate. Whereas the students could list an average of 9.0 crops, 8.4 trees, and 5.4 garden flowers correctly, they could list only 1.9 vines, 1.7 wildflowers/weeds, and 1.4 grasses correctly. Incorrect answers (answers that were wrong or inappropriate) were listed by $22.5 \%$ to $58.0 \%$ of the students depending on the domain. The types of incorrect answers given indicate a fuzzy understanding or knowledge of local ecology, plant morphology or habit, and domesticated versus wild or weedy status. Results indicate the solicited life forms or domains of plants hold unequal cultural saliency for this selection of students. Knowledge appears highest for crops, trees (particularly planted trees), and showy garden flowers, reflecting highest familiarity with the surrounding managed landscape and least familiarity with wild and less noticeable vegetation. Some answers reflect vicarious knowledge of plants rather than knowledge gained through direct experience. This study points out the need to carefully consider which domains of plant knowledge should be compared cross-culturally, and the need to quantify and examine incorrect as well as correct answers.
\end{abstract}

\section{Introduction}

A handful of studies on the botanical knowledge of people, especially children and students, hints that American botanical novices and others from industrialized nations or non-resource-dependent communities know relatively few of the plants that grow around them compared to experts or people in societies who live close to nature (e.g., Atran et al. 2004, Coley et al. 1997:106-107, Hunn 2002, Pilgrim et al. 2007, 2008, Shipman \& Boster 2008, Witkowski et al. 1981). Knowledge of local plants is one proxy of eco- literacy, and ecoliteracy is necessary for sustainable resource management and support of conservation efforts (e.g., Pilgrim et al. 2007, 2008). I report on the first stage of study of the botanical knowledge of college students in South Carolina, U.S.A. In particular, I address issues of comparability or commensurable domains of analysis for cross-cultural studies of botanical knowledge, and I submit a plea to researchers to examine and report both the correct and incorrect answers they receive.

\section{Methods}

Thirty-one students between ages 18-22 were asked to freelist garden flowers, locally-growing grasses, local domesticated crops, and native/local trees, vines, and wildflowers/weeds. Informants were not chosen by any statistical sampling strategy: their recruitment was at the discretion of the interviewers, who were themselves, undergraduate students at the University of South Carolina. Answers were scored as correct, wrong, or inappropriate. Responses were run through ANTHROPAC 4.0 (Borgatti 1996) to examine cultural consensus.

\section{Correspondence}

Gail E. Wagner, Department of Anthropology and School of the Environment, University of South Carolina, Columbia, South Carolina, U.S.A.

gail.wagner@sc.edu

Ethnobotany Research \& Applications 6:443-458 (2008)

Published: December 26, 2008 
Freelisting is an interview technique in which the person interviewed is asked to list members of or items in a cultural domain (Borgatti 1996, Puri \& Vogl 2005:13-14, Quinlan 2005). Our understanding of what a freelist imparts is based on three assumptions: (1) people tend to list items in order of familiarity; (2) experts list more items than do novices; and (3) people tend to list locally noteworthy items (Quinlan 2005). However, freelists can also "contain runs of items that are strongly related" (Borgatti 1996:3). The mental organization that results in clustering recall contributes to the ability to produce a longer list (Shipman \& Boster 2008:178-182). Freelists tend to be more complete the more focused the domain (Quinlan 2005). Thus, it is better to ask for the names of locally growing trees, or local vines, as was done in this study, rather than ask for a list of all the plants that grow locally (e.g., Gatt et al. 2007). The analysis of freelists involves a number of recurrent problems, including the listing of synonyms and the inclusion of terms at different levels of contrast (such as evergreen at the intermediate folk biological level, pine at the generic level, and loblolly pine at the specific level) (Borgatti 1996:2). Freelists cannot be used by themselves to reliably measure botanical knowledge. The freelists solicited for this study are simply the first stage in a multiyear project on botanical knowledge.

The data were collected by 16 undergraduate students in an ethnobotany course during the fall semester of 2007 , following university IRB approval of human subject research. Using a standardized interview form, each student collected two interviews of other university students 18-22 years in age. Informants were asked to list members of each domain that they thought they could recognize in the field. Student interviewers were instructed to ask for the six different lists in different orders: some did, and some did not. Whether vines or any other domain were asked for first or last appears to have had no effect on the lengths of each list solicited.

The six domains solicited are, themselves, not at equal folk taxonomic ranks or levels of contrast. Whereas tree, vine, and grass are folk biological life forms, the other three domains (crop, garden flower, and wildflower/weed) are artificial in nature (however, Coley et al. 1997:87 consider flower to be more or less a life form for urbanized Americans). Two, crop and garden flower ("flower"), were designed to ask informants about domesticated plants grown locally and seem to have been relatively well understood. The major problem encountered with the domain of garden flower was the listing of flowering trees and shrubs, which were counted as inappropriate. Interviewers were instructed to specifically ask for non-trees and non-shrubs, but whether they each did so cannot be verified. The wildflower/weed ("weed") category was designed to ask about non-planted plants and presented an opportunity for informants to display knowledge of native, wild plants. Nevertheless, the term "local" we used to solicit lists does not distinguish between native and introduced plants, but merely posits that the plants grow (implied outdoors) in the state of South Carolina. I believe that asking informants to list local plants emphasizes identification and knowledge based more on direct rather than vicarious experience of nature.

I categorized individual answers or domain members as correct, wrong, or inappropriate. I relied on my own "expert" knowledge as a botanist and member of the society we interviewed (see Atran et al. 2004, Shipman \& Boster 2008). When I was unsure, I consulted southeastern botanical reference books (Batson 1987, Bell \& Taylor 1982, Brown \& Kirkman 1990, Duncan \& Duncan 1988, Radford et al. 1968, Weakley 1997) and the U.S.D.A. PLANTS database (USDA, NRCS 2008). I considered an answer to be wrong when it was not a member of the domain or when it was listed at the folk biological intermediate level or higher (with the exception of listing "evergreens" as a crop) (Table 1). I considered an answer to be inappropriate when it was a member of the domain, but did not fit other criteria, such as growing in the state of South Carolina (Table 2). l'll return to the utility of using wrong and inappropriate answers as a proxy of botanical knowledge, but for now l'll group them together as incorrect.

Scoring some of the answers as wrong or inappropriate proved to be a difficult judgment call on my part as the expert (Tables 1-3), and when I was less than certain of

Table 1. Examples of wrong answers received when South Carolina, U.S.A. college students were asked to freelist garden flowers, local grasses, local crops, and native/local trees, vines, and wildflowers/weeds.

\begin{tabular}{|l|l|l|l|l|l|}
\hline Crop & Tree & Flower & Weed & Vine & Grass \\
\hline Aloe & Aloe & Bamboo & Clover & Dandelion & Cattail \\
Grain & Acorn & Crabgrass & Elephant ear & Poison oak & Dune \\
Mulberry & Azalea & Dandelion & Fennel & Poison sumac & Lawn \\
& Bamboo & Elephant ears & Fern & Spanish moss & Marsh \\
& Bonsai & Posies & Grass & & Millipede \\
& Evergreen & & Hosta & & Monkeygrass \\
& Fern & & Sarijuana & & Sea \\
& Hardwood & & Monkeygrass & & Wild \\
& Oleander & & & & \\
& & & & & Winter \\
\hline
\end{tabular}




\section{Wagner - Botanical Knowledge of a Group of College Students in South Carolina, U.S.A.}

Table 2. Examples of inappropriate answers received when South Carolina, U.S.A. college students were asked to freelist garden flowers, local grasses, local crops, and native/local trees, vines, and wildflowers/weeds.

\begin{tabular}{|l|l|l|l|l|}
\hline Crop & Tree & Flower & Weed & Vine \\
\hline Chickpea & Grapefruit & African violet & Baby's breath & Pumpkin \\
Cranberry & Mahogany & Azalea & Blueberry & Raspberry \\
Grapefruit & Orange & Camellia & Daisy & Tomato \\
Marijuana & Palm & Gardenia & Marigold & \\
Orange & Pomegranate & Honeysuckle & Sunflower & \\
& Redwood & Hydrangea & Zinnia & \\
& Sago palm & Jasmine & & \\
& & Lilac & & \\
& & Magnolia & & \\
\hline
\end{tabular}

a. Judgement call on my part that students do not know wild sunflowers, but instead pictured domesticated sunflower.

the categorization I at least was consistent. For example, whereas jasmine was scored as inappropriate (not local) when listed as a flower, yellow jasmine was accepted as a weed because I considered it to be a mispronunciation or mis-recording of the South Carolina official state (wild) vine, the yellow jessamine. The listing of fennel as a weed was considered wrong, although I would have accepted fennel as a crop or dog-fennel as a weed. Another category particularly difficult to classify was palm. Even though a few tropical palms are planted in South Carolina, I counted most palm answers as inappropriate. My evaluation was based on what palms are sold at horticultural outlets and which are listed as present in South Carolina in the PLANTS Database (USDA, NRCS 2008). The cabbage palmetto (Sabal palmetto (Walter) Lodd. ex
Schult. \& Schult. f.) is our state tree, a fact well known by all students raised in the state. It remains to be explored whether "palm" is sometimes used by South Carolinians as shorthand for "palmetto".

Answers were input into the software program ANTHROPAC for consensus analysis (Borgatti 1996). Consensus analysis estimates both the cultural knowledge of each informant and the culturally correct answers (Romney 1999, Romney et al. 1996:4700-4701). It assumes three conditions are met: (1) the people interviewed are from one culture that holds a common truth; (2) responses are independent; and (3) all the questions focus on one domain (Borgatti 1996:44). Consensus analysis can

Table 3. Examples of correct answers received when South Carolina, U.S.A. college students were asked to freelist garden flowers, local grasses, local crops, and native/local trees, vines, and wildflowers/weeds.

\begin{tabular}{|l|l|l|l|l|l|}
\hline Crop $^{\mathbf{a}}$ & Tree $^{\mathbf{a}}$ & Flower $^{\mathbf{a}}$ & Weed $^{\mathbf{b}}$ & Vine $^{\mathbf{b}}$ & Grass $^{\mathbf{b}}$ \\
\hline Blueberry & Apple & Chrysanthemum & Black-eyed & Clematis & Bermuda \\
Cabbage & Birch & Daffodil & Susan & Grape & Bluegrass \\
Carrot & Cedar & Daisy & Buttercup & Honeysuckle & Broomstraw \\
Corn & Cherry & Iris & Cattail & Ivy & Centipede \\
Cotton & Crape myrtle & Lily & Crabgrass & Kudzu & Crabgrass \\
Cucumber & Cypress & Pansy & Dandelion & Poison ivy & Fescue \\
Onion & Dogwood & Rose & Honeysuckle & Virginia creeper & Indian grass \\
Peach & Fir & Snapdragon & Indian tobacco & Wisteria & Lemon \\
Peanut & Holly & Sunflower & Jessamine & Yellow jessamine & Pampas \\
Pumpkin & Magnolia & Tulip & Kudzu & & Rye \\
Rice & Maple & Violet & Morning glory & & Sawgrass \\
Soybean & Oak & & Onion & & Zoysia \\
Squash & Palmetto & & Queen Anne's & & \\
Strawberry & Peach & & lace & & \\
Tobacco & Pear & & Rabbit tobacco & & \\
Tomato & Pecan & & Ragweed & & \\
Watermelon & Pine & & Sandspur & & \\
Wheat & Willow & Stinkweed & & \\
& Weeping willow & & Violet & & \\
& & Wisteria & & \\
\end{tabular}

a. Correct names listed by 5 or more students.

b. All correct names listed by any student under that domain. 
be performed with small sample sizes (Romney et al. 1986:325-326).

Computation of the eigenvalues of the answer matrix allows one to assess the likelihood that the informants belong to one culture. If the ratio of the first to the second eigenvalue is less than 3 to 1 , you cannot make the assumption of one culture. A ratio of 10 to 1 or more is strong support of the one-culture assumption. That is, the group of people interviewed appear to give the same pattern of response (Borgatti 1996:44). Four of the six domains examined (crop, tree, flower, and weed) returned eigenvalues that strongly support my assumption that the students interviewed belong to one culture (Table 4). The closer the reliability measure to 1.00 , the higher the consensus, and the informants show high consensus in all six domains.

Table 4. Demonstration of one culture from responses when South Carolina, U.S.A. college students were asked to freelist garden flowers, local grasses, local crops, and native/local trees, vines, and wildflowers/weeds.

\begin{tabular}{|l|c|c|c|c|}
\hline & $\begin{array}{c}\text { First } \\
\text { Eigenvalue }\end{array}$ & Percent & $\begin{array}{c}\text { Ratio } \\
\mathbf{1 : 2}\end{array}$ & $\begin{array}{c}\text { Pseudo- } \\
\text { Reliability }\end{array}$ \\
\hline Crop & 19.1 & 90.8 & 18.2 & 0.978 \\
\hline Tree & 19.5 & 92.1 & 23.0 & 0.979 \\
\hline Flower & 21.9 & 94.4 & 32.0 & 0.985 \\
\hline Weed & 21.5 & 94.4 & 30.9 & 0.989 \\
\hline Vine & 16.0 & 78.2 & 6.0 & 0.968 \\
\hline Grass & 14.8 & 85.1 & 8.7 & 0.976 \\
\hline
\end{tabular}

Note: Data computed in consensus analysis through ANTHROPAC 4.0 (Borgatti 1996).

Percent: Percent to which the first factor explains the responses of informants.

Ratio: Ratio of first eigenvalue to second eigenvalue.

\section{Results}

Informants reached consensus on only a few members of five of the six domains (Table 5). No consensus was reached on the members of grass, although the two most common answers were crabgrass and bluegrass. One student remarked, "I didn't know there were different kinds of grass" (Informant 007, 22-year-old male). Student lists agreed on four crop plants, four trees, two flowers, and only one each of weeds and vines. If the freelists we solicited were an end in themselves, these core items could be seen as the most salient members of each domain for students between ages 18-22 (Borgatti 1996:2). Instead, they provide a list of domain members that should be included in plant identification tasks in future work on this project.

Of the three categories or domains of plants that were solicited, two clearly stand out from the others (Appendix 1a-f). Students listed far more correct names of crops and
Table 5. Consensus on domain members when South Carolina, U.S.A. college students were asked to freelist garden flowers, local grasses, local crops, and native/local trees, vines, and wildflowers/weeds.

\begin{tabular}{|l|c|l|}
\hline & Number & Members \\
\hline Crop & 4 & Corn, cotton, tomato, tobacco \\
\hline Tree & 4 & Oak, pine, maple, dogwood \\
\hline Flower & 2 & Tulip, rose \\
\hline Weed & 1 & Dandelion \\
\hline Vine & 1 & Kudzu \\
\hline Grass & 0 & \\
\hline
\end{tabular}

Note: although scientific names were not solicited or given, the following scientific names may be assigned to the above answers: corn (Zea mays), cotton (Gossypium), tomato (Solanum lycopersicum), tobacco (Nicotiana tabacum), oak (Quercus), pine (Pinus), maple (Acer), dogwood (Cornus), tulip (Tulipa), rose (Rosa), dandelion (Taraxacum officinale), kudzu (Pueraria montana).

trees than they did the other categories. They were somewhat cognizant of garden flowers. They listed few wildflowers/weeds, grasses, or vines. On average, students correctly listed 9.0 crops, 8.4 trees, and 5.4 garden flowers, but only 1.9 vines, 1.7 weeds, and 1.4 grasses. Whereas every student interviewed correctly listed one or more in each of crops, trees, and flowers, $4 \%$ could list no wildflower/weed, $19 \%$ could list no vine, and $35 \%$ could list no grasses (Figure 1). However, $50 \%$ could list only one wildflower/weed correctly, and $93 \%$ of those listed dandelion, an introduced weed common in lawns. The majority could correctly list four or more items among crops, trees, and garden flowers, but three or fewer items among weeds, vines, and grasses (Figure 2).

The domain with the fewest students supplying incorrect compared to correct answers was local crops (Figure 1). Not only did $77 \%$ of the students give no wrong or inappropriate answers, those answers that were incorrect tended to be either too general (e.g., grains, legumes) or not grown locally (e.g., chickpea, grapefruit). It seems our respondents used the connotation of "crops" to frame the appropriateness of their answers when our use of the additional phrase "local vegetables" by itself would likely have been too confusing (see Wagner 2006). For example, answers I counted as correct include cotton, tobacco, indigo, tea, alfalfa, and evergreens, all crops grown commercially now or in the past in South Carolina (Table 3).

The next fewest incorrect answers were for vine and grass, which are also domains with the fewest correct answers (Tables 1-3, Figure 1). Whereas I interpret the lack of wrong/inappropriate answers for crops to indicate knowledge of the domain, I interpret the same results with vine and grass to indicate lack of knowledge of the domains! The types of incorrect answers were different from those 

in South Carolina, U.S.A.

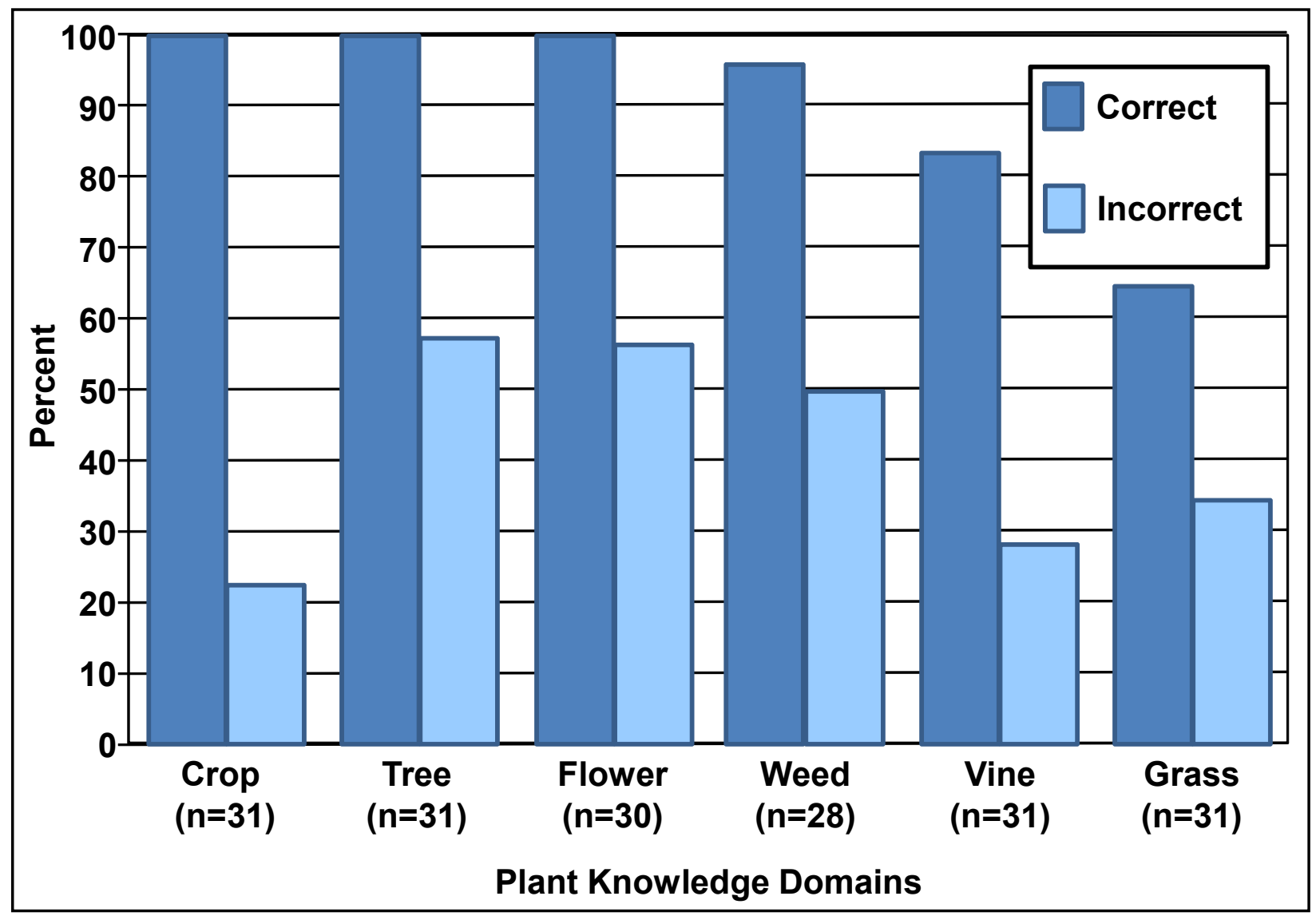

Figure 1. Percent of students who gave any correct answers vs percent who gave any incorrect answers.

for crops, and included names that were descriptive (e.g., dune, summer, winter, lawn, or marsh grass), misidentifications of plants that share some aspects of members of the domains (e.g., monkeygrass or cattail for grass, Spanish moss for vine), or inclusion of plants that are not wild or naturalized (e.g., pumpkin and tomato vines). Fully $32 \%$ of the 31 students listed vines under the domains of garden flowers or wildflower/weeds, but did not repeat the same names under the domain of vine (hinting that the life form of vine holds little overall importance to them). Only $6 \%$ of the students listed a vine under another domain and also repeated the same name under the domain of vine.

The domains with $50 \%$ or more of the students supplying incorrect answers were tree (58\%), garden flower (57\%), and wildflowers/weeds (50\%) (Figure 1). Incorrect answers indicate a fuzzy understanding or knowledge of local ecology (e.g., differentiating local from not-local trees), plant morphology or habit (e.g., failure to double classify certain flowers or weeds as vines, trees, or shrubs), and domesticated versus wild or weedy status (e.g., listing domesticated plants under wildflower/weed) (Tables 1-3).

\section{Discussion and Conclusions}

Does a relationship exist between naming members of a domain in a freelist and knowledge of the members of that domain? Knowledge has many dimensions, including identifying or recognizing the plant, and understanding its place in natural and cultural dimensions or relationships (e.g., Berkes 1999, Coley et al. 1997, Nolan 2001, Shipman \& Boster 2008). Would students be able to recognize and identify the plants they list, or are their answers simply names to them? When the students list a name, do they also, however briefly, hold a mental representation? In one of the earliest studies of botanical knowledge of children, six 3-8-year-old American children named genera that they couldn't identify. However, they also recognized more genera than they could name (Dougherty 1978).

Cognitive psychologists, who seek "to understand how categories are learned and used" (Markman \& Ross 2003:592), posit that categories or domains are acquired through interaction with the domain and its members (Markman \& Ross 2003:592). Even students of folk biological classification agree that categorization of plants follows some logic of cultural salience (Hays 1982, Malt et al. 1999:259). However, naming can be separated from 


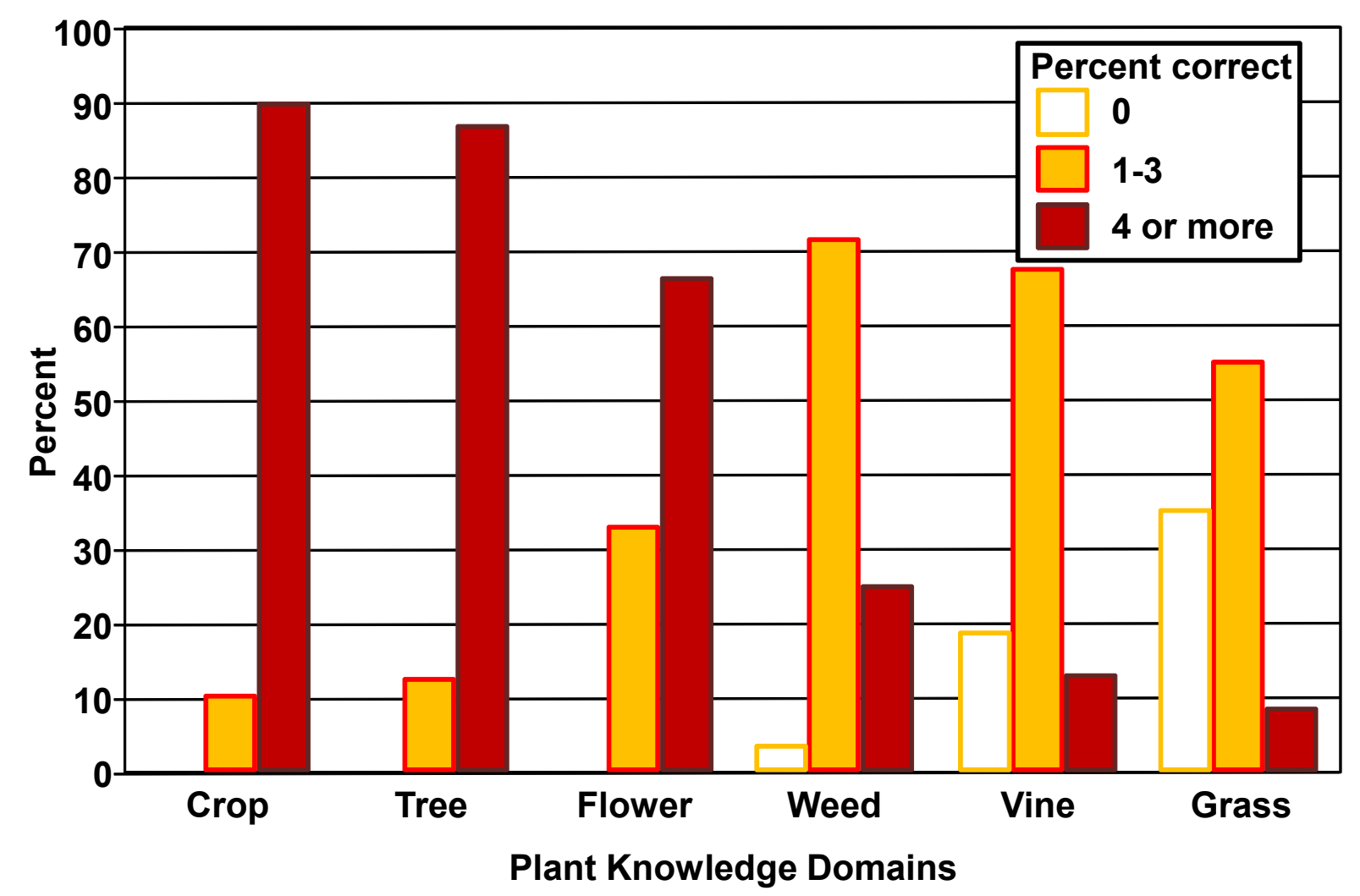

Figure 2. Ranges of correct answers by percent of students.

conception and may follow culturally specific rules that have been affected by history (Malt et al. 1999).

In an industrialized country such as America, children may interact with nature not only directly (as in playing in the woods), but also indirectly (as in structured interaction at a botanical garden) and vicariously (as in viewing TV or the internet) (Kellert 2002). The marked decrease in direct experience of nature and the rise in indirect and vicarious experience of nature are of concern (Kellert 2002, Louv 2006, Pergams \& Zaradic 2006). I believe this changing balance of nature experience affects a person's knowledge of plants in ways that will not be simple to deconstruct (e.g., Shipman \& Boster 2008). If the majority of one's knowledge of plants derives from direct experience that is both unregulated (such as play) and regulated (such as gathering useful plants) in culturally relevant contexts, then not surprisingly one may be able to identify many plants, correctly name or freelist many plants because those plants will hold salience in the culture, name few to no incorrect plants, and display knowledge of how plants relate to the cultural and natural world. If the majority of one's knowledge of plants derives from indirect or vicarious experience usually lacking a culturally relevant context, then one may be able to name more plants than one can actually identify, and local knowledge may be low.
Knowledge of local, wild plants does seem to be low among the South Carolina students interviewed. Whereas an average of 5.4-9.0 domesticated garden flowers and crops, respectively, were listed, an average of less than 2.0 vines, wildflower/weeds, and grasses were listed (Appendix 1$)$. It is true that $61-67 \%$ of the 18 different wildflower/ weeds and $56 \%$ of the 9 different vines correctly listed are native, but the overall variety of names remains low. Only $25 \%$ of the 12 types of grass listed are wild grasses native to South Carolina (broomstraw, Indian grass - our State grass, and sawgrass). The remaining $75 \%$ are ornamental, garden, lawn, or introduced, weedy grasses (Table 3). Of the 55 correctly listed types of trees, only three $(5 \%)$ are found mostly in wild areas (black locust, mountain laurel, and sassafras): the rest are often encountered in yards and plantings. All of the inappropriate trees named by the students in this study may be interpreted to reflect vicarious knowledge (Table 2). Students listed five genera or families of tropical trees and one from the Pacific rainforest, even though they were asked to list local trees they thought they could recognize in the field.

The folk taxonomic level at which answers were given differed by domain. The most specific answers were given in the two domains that students seem to know best, crops and trees. Altogether $32 \%$ of students listed crop varieties, and $77 \%$ of students listed tree species. The majority 


\section{Wagner - Botanical Knowledge of a Group of College Students in South Carolina, U.S.A.}

of tree species listed were of cultivated trees, often trees with primary lexeme names (e.g., apple, pear, cherry, peach, pecan, fig, palm) or trees with only one local representative in tree form, rendering an answer at the species level by default (e.g, apple, chinaberry, crape myrtle, fig, mimosa, palmetto, sassafras). In all but one case, those who listed tree species whose specific names require an adjective modifier first listed that tree at a generic level before listing species.

As others have pointed out (Brown 1958 in Markman \& Ross 2003:593, Malt et al. 1999:260), informants supply answers at different levels of abstraction (e.g., evergreen, pine, loblolly pine). Answers depend, in part, on the level at which the informant can identify any particular plant. Additionally, the informant makes a determination about which level of answer will be acceptable. Worldwide, the generic folk biological rank is seen as the most numerous and salient (Atran et al. 2004:397, Brown 2000, Dougherty 1978), a generalization that has been found to hold true even for American students with novice knowledge of plants (Coley et al. 1997, Medin \& Atran 2004, Tull 1994). Earlier studies appeared to disagree, finding less specific terms such as the life form rank an increasingly acceptable and salient level of answer in urbanized societies divorced from daily nature contact (Dougherty 1978, Witkowski et al. 1981). Rather, people in societies divorced from daily nature contact are likely to understand the properties of a folk genus, but unlikely to be able to identify plants and their uses at that and finer ranks (Coley et al. 1997).

When the average American college student looks at the landscape around him/her, how sharp is his/her focus? Is vegetation vaguely varied and green (e.g., Shipman \& Boster 2008), or are various life forms such as tree or vine recognized? Several studies indicate that tree, grass, and vine life forms are recognized and differentiated by very young children (Dougherty 1979, Gatt et al. 2007). Does recognition stop at the generic level? When does it proceed to the specific or varietal level? The answers to these questions surely are both culturally situated (i.e., what plants are necessary or important to know) and dependent on the individual's preferences and life history (i.e., what plants are also of interest).

Our concentration as ethnobiologists on comparing taxonomic or ecological domain knowledge between resourcedependent and non-resource dependent societies rather than on salient domains creates a methodological flaw in how a number of studies of plant knowledge in industrialized societies are conceived and compared with studies of plant knowledge in resource-dependent societies (see Medin \& Atran 2004, Reyes-Garcia et al. 2007 for other methodological flaws). It is obvious from the present study that different life forms or domains of plants hold different cultural saliency. In particular, wildflowers/weeds, vines, and grasses are not particularly important or of interest to most of the American college students we interviewed.
Whereas students can name a variety of trees and garden flowers, their knowledge appears centered on trees that are planted and on showy garden flowers, including flowering shrubs and trees even though the solicitation of garden flowers was for non-shrubs/trees. Students' longest freelists with the highest frequency of correct answers were of domesticated local crops. For the most part, the familiar landscape around these college students is a managed one with many planted genera, and it is not unreasonable to state that for many Americans, individual wild plants hold little cultural salience.

When we ask people in industrialized societies to name wild plants or forest trees, in one sense we are not asking for knowledge comparable to the knowledge we seek when we ask the same questions of resource-dependent societies for whom those domains hold some cultural salience (Cooper 2008). If our goal is to compare local ecological knowledge of what have become for industrialized societies historic, rare, or nonexistent natural ecosystems, we should ask about local, native plants. However, if our goal is to compare botanical knowledge in general, we should compare comparably salient domains. Zarger and Stepp (2004) noted that even among Tzeltal Mayan children, culturally significant plants, including those that are cultivated, protected, or otherwise culturally salient, were correctly identified more frequently than were culturally unimportant plants. Cultivated species were correctly identified $70 \%$ of the time (Zarger \& Stepp 2004). Prior to intervention, among ten $4^{\text {th }}-5^{\text {th }}$ grade $(9-12$-yearold) South Carolina elementary school students, food and crop plants were correctly identified $71 \%$ and plants with multiple uses $60 \%$ of the time, whereas wild plants were correctly identified only $18 \%$ and ornamental plants $15 \%$ of the time (Cooper 2008).

All too often, surveys of children from industrialized, nonresource-dependent societies concentrate on measuring knowledge of wild or culturally unimportant plants. Of the over $3,00010^{\text {th }}$ graders in Germany who were asked to name eight wildflowers native to the country, approximately $20 \%$ could not name any (Demuth 1992 in LindemannMatthies 2005). Only $15 \%$ of first-year undergraduate biology majors could name ten flowers native to Germany (Hesse 1983 in Lindemann-Matthies 2005). In the United Kingdom, $85 \%$ of 812 A-level (16-18-year-old) biology students could identify only three or fewer of ten colored drawings of common wildflowers (Bebbington 2005). American students at Northwestern University tended to identify trees only at the life-form rank of "tree" (Atran et al. 2004:404). Although the studies l've just mentioned were laudable in that they attempted to measure knowledge of local flora, they were inappropriate in that they did not seek to measure salient botanical knowledge.

It is a sad fact that much of the local native flora may not be culturally salient to people in industrialized societies. Is it surprising that 109 UK 4-11-year-old schoolchildren 
could identify $50 \%$ or less of ten types of British wildlife (at least two of which were plants), but by age 8 nearly $80 \%$ of Pokemon characters (Balmford et al. 2002)? Given the documented decrease in direct experience with local wild nature (Kareiva 2008, Pergams \& Zaradic 2008), the pervasiveness of human-shaped habitats with numbers of introduced species, the documented rise in vicarious experience of non-local nature (Pergams \& Zaradic 2006), and the probability that most local flora is viewed from the window of a vehicle (thus, a focus on trees as opposed to smaller flora: see Hunn 1999), it is not surprising that the American 18-22-year-old college students we interviewed name more crops and trees than garden flowers, local wildflowers/weeds, local vines, or local grasses. It is not surprising that the majority of trees named to the specific level are domesticated (e.g., apple, peach), prominent in vicarious sources (e.g., weeping willow, redwood), or commonly planted (e.g., Japanese maple, crape myrtle).

Studies that do not clearly distinguish between correct and incorrect names not only ignore a rich corpus for interpretation, but render them unfit for comparison, even within the same culture. For example, 33 University of Connecticut college students who were asked to name trees listed 6-42 trees (mean 18.0) (Shipman \& Boster 2008). In comparison, the 31 University of South Carolina students seem incompetent because they listed 2-25 trees correctly (mean 8.4). However, not only were non-native tree names such as palm, orange, olive, mangrove, and cypress accepted for the University of Connecticut students, but also descriptive and life-form names (e.g., Christmas tree, Easter tree, evergreen) appear to have been counted. All names such as these were discounted as incorrect for the University of South Carolina students.

Given that for this project, freelisting is just the first step in a multi-year study, what else can be learned from the 31 freelists obtained? First, the freelists provide a minimal list of what plants to ask informants to actually identify, either on a plant trail or in pictures. The types of inappropriate answers recorded indicate that a more detailed definition of the domains of garden flower and wildflower/weed should be made clear when the domain is solicited. The potential differences and overlaps among the six domains could be highlighted in a brief discussion prior to asking for the freelists. Interviews could be conducted on defining the domains.

The next step of this project will focus on field identification or picture identification of selected domains. I predict that students can list more crops than they can identify unless the edible portion of the plant is visible. For example, I predict that most students will not know soybean, peanut, or cotton when only the vegetation of a non-flowering or fruitless plant is visible. I also predict that given a list of plant names, students will be able to correctly place more names in domain categories than they thought to freelist. However, they may not perform as well on pile sorts of pictures when obvious characteristics such as edible portions or fruits are not visible (see Shipman \& Boster 2008:174 on differences between sorting names and sorting pictures). In other words, I believe their overall botanical knowledge is shallow and based more on vicarious and indirect, highly individualized experience rather than direct experience that is culturally salient.

I can make some predictions about the sorts of correct and incorrect answers one might receive from two ends of a spectrum of plant knowledge. For someone with direct experience of plants through culturally salient experience, I expect a high number of correct names and a low number or absence of incorrect names. Names will be at the generic or more specific levels. The informant will be knowledgeable about local plants. For someone with mostly vicarious and indirect experience of plants with little culturally salient experience, I expect a high number of incorrect names, with some answers describing rather than naming; some answers individually unique rather than culturally recognized; and some categorizations at a suprageneric level. Informants may incorrectly list plants that have similar names or physical aspects to the domain under question. They also may not recognize co-membership in multiple domains. Knowledge of local, wild plants is likely to be low.

I hope I have brought two methodological issues to the forefront in this article: (1) the need to closely examine what categories or domains of plants are solicited, and particularly to base cross-cultural comparisons more on the basis of culturally salient domains rather than taxonomic domains; and (2) the need to quantify correct vs incorrect answers, as well as to specify the ways in which answers were incorrect.

\section{Acknowledgments}

My thoughts on this subject have benefited from my conversations with Chanda Cooper. My thanks are also extended to the students who conducted the interviews: Scott Anderson, Eric Brei, Christina Carroll, William Cely, Sydney Daigle, Anna Gallery, John W. Hicks, James T. Horne, Matt Hunter, Zack Klicka, Brian Koppal, Scarlett Luther, Ester Marvin, Sebastian Pena, Stacy Ross, and Will Tonking.

\section{Literature Cited}

Atran, S., D. Medin \& N. Ross. 2004. Evolution and devolution of knowledge: A tale of two biologies. Journal of the Royal Anthropological Institute 10:395-420.

Balmford, A., L. Clegg, T. Coulson, \& J. Taylor. 2002. Why conservationists should heed Pokemon. Science 295(5564):2367. 


\section{Wagner - Botanical Knowledge of a Group of College Students in South Carolina, U.S.A.}

Batson, W.T. 1987. Wild Flowers in the Carolinas. University of South Carolina Press, Columbia.

Bebbington, A. 2005. The ability of A-Level students to name plants. Journal of Biological Education 39(2):6367.

Bell, C.R. \& B.J. Taylor. 1982. Florida Wild Flowers and Roadside Plants. Laurel Hill Press, Chapel Hill, NC.

Berkes, F. 1999. Challenges to indigenous knowledge. Pp. 145-161 in Sacred Ecology: Traditional ecological knowledge and resource management. Edited by F. Berkes. Taylor \& Francis, Philadelphia.

Borgatti, S.P. 1996. ANTHROPAC 4.0 Methods Guide. Analytic Technologies, Natick, MA.

Brown, C.H. 2000. Folk classification: An introduction. Pp. 65-68 in Ethnobotany, A Reader. Edited by P.E. Minnis. University of Oklahoma Press, OK.

Brown, C.L. \& L.K. Kirkman. 1990. Trees of Georgia and Adjacent States. Timber Press, Portland, OR.

Coley, J.D., D.L. Medin, \& S. Atran. 1997. Does rank have its privilege? Inductive inferences within folkbiological taxonomies. Cognition 64:73-112.

Cooper, C.L. 2008. Botanical knowledge of a group of South Carolina Elementary School Students. Ethnobotany Research \& Applications 6:121-127.

Dougherty, J.W.D. 1978. Salience and relativity in classification. American Ethnologist 5:66-80.

Dougherty, J.W.D. 1979. Learning names for plants and plants for names. Anthropological Linguistics 21(6):298315.

Duncan, W.H. \& M.B. Duncan. 1988. Trees of the Southeastern United States. University of Georgia Press, Athens.

Gatt, S., S.D. Tunnicliffe, K. Borg, \& K. Lautier. 2007. Young Maltese children's ideas about plants. Journal of Biological Education 41(3):117-121.

Hays, T.E. 1982. Utilitarian/adaptionist explanations of folk biological classification: Some cautionary notes. Journal of Ethnobiology 2:89-94.

Hunn, E.S. 1999. Size as limiting the recognition of biodiversity in folkbiological classifications: One of four factors governing the cultural recognition of biological taxa. Pp. 47-70 in Folkbiology. Edited by D.L. Medin \& S. Atran. Bradford Book, MIT Press, Cambridge, Massachusetts.
Hunn, E.S. 2002. Evidence for the precocious acquisition of plant knowledge by Zapotec children. Pp. 604-613 in Ethnobiology and Biocultural Diversity. Edited by J.R.

Stepp, F.S. Wyndham, \& R.K. Zarger. International Society of Ethnobiology, Athens, Georgia.

Kareiva, P. 2008. Ominous trends in nature recreation. Proceedings of the National Academy of Science 105(8):2757-2758.

Kellert, S.R. 2002. Experiencing nature: Affective, cognitive, and evaluative development in children. Pp. 117-151 in Children and Nature: Psychological, Sociocultural, and Evolutionary Investigations. Edited by P.H. Kahn, Jr. \& S.R. Kellert. MIT Press, Cambridge, Massachusetts.

Lindemann-Matthies, P. 2005. 'Loveable' mammals and 'lifeless' plants: How children's interest in common local organisms can be enhanced through observation of nature. International Journal of Science Education 27(6):655677.

Louv, R. 2006. Last Child in the Woods: Saving our children from nature-deficit disorder. Algonquin Books, Chapel Hill, NC.

Malt, B.C., S.A. Sloman, S. Gennari, M. Shi, \& Y. Wang. 1999. Knowing versus naming: Similarity and the linguistic categorization of artifacts. Journal of Memory and Language 40:230-262.

Markman, A.B. \& B.H. Ross. 2003. Category use and category learning. Psychological Bulletin 129(4):592-613.

Medin, D.L. \& S. Atran. 2004. The native mind: Biological categorization and reasoning in development and across cultures. Psychological Review 111(4):960-983.

Nolan, J.M. 2001. Pursuing the fruits of knowledge: Cognitive ethnobotany in Missouri's Little Dixie. Journal of Ethnobiology 23:29-51.

Pergams, O.R.W. \& P.A. Zaradic. 2006. Is love of nature in the US becoming love of electronic media? 16-year downtrend in national park visits explained by watching movies, playing videogames, internet use, and oil prices. Journal of Environmental Management 80:387-393.

Pergams, O.R.W. and P.A. Zaradic. 2008. Evidence for a fundamental and pervasive shift away from nature-based recreation. Proceedings of the National Academy of Science 105(7):2295-2300.

Pilgrim, S., D. Smith, \& J. Pretty. 2007. A cross-regional assessment of the factors affecting ecoliteracy: Implications for policy and practice. Ecological Applications 17:1742-1751. 
Pilgrim, S.E., L.C. Cullen, D.J. Smith, \& J. Pretty. 2008. Ecological knowledge is lost in wealthier communities and countries. Environmental Science \& Technology 42(4):1004-1009.

Puri, R.K. \& C.R. Vogl. 2005. A Methods Manual for Ethnobiological Research and Cultural Domain Analysis Using ANTHROPAC. Unpublished.

Quinlan, M. 2005. Considerations for collecting freelists in the field: Examples from ethnobotany. Field Methods $17: 219-234$.

Radford, A. E., H.E. Ahles, \& C.R. Bell. 1968. Manual of the Vascular Flora of the Carolinas. University of North Carolina Press, Chapel Hill.

Reyes-Garcia, V., N. Marti, T. McDade, S. Tanner, \& V. Vadez. 2007. Concepts and methods in studies measuring individual ethnobotanical knowledge. Journal of Ethnobiology 27:182-203.

Romney, A.K. 1999. Culture consensus as a statistical model. Current Anthropology 40:S103-S115.

Romney, A.K., S.C. Weller \& W.H. Batchelder. 1986. Culture as consensus: A theory of culture and informant accuracy. American Anthropologist 88:313-338.

Romney, A.K., J.P. Boyd, C.C. Moore, W.H. Batchelder, \& T.J. Brazill. 1996. Culture as shared cognitive representa- tions. Proceedings of the National Academy of Science 93:4699-4705

Shipman, A.C.S. \& J.S. Boster. 2008. Recall, similarity judgment, and identification of trees: A comparison of experts and novices. Ethos 36(2):171-193.

Tull, D. 1994. Elementary students' responses to questions about plant identification: Response strategies in children. Science Education 78:323-343.

USDA, NRCS. 2008. The PLANTS Database. National Plant Data Center, Baton Rouge, LA. http://plants.usda. gov (verified 3 August 2008).

Wagner, G.E. 2006. The Saliency of "Vegetable." Paper presented at the Society for Economic Botany annual meeting, Chiang Mai, Thailand.

Weakley, A.S. 1997. Flora of the Carolinas and Virginia (Working Draft of 6 May 1997). The Nature Conservancy Southeast Regional Office, Chapel Hill, NC.

Witkowski, S.R., C.H. Brown, \& P.K. Chase. 1981. Where do tree terms come from? Man, N.S. 16:1-14.

Zarger, R.K. \& J.R. Stepp. 2004. Persistence of botanical knowledge among Tzeltal Maya children. Current Anthropology 45:413-418. 


\section{Wagner - Botanical Knowledge of a Group of College Students in South Carolina, U.S.A.}

Appendix 1a. Number of South Carolina crops freelisted by informant. Number of correct answers listed at varietal level (Variety), Not recorded (NR).

\begin{tabular}{|c|c|c|c|c|c|c|c|}
\hline Informant & Age & Sex & Total Number & Correct & Wrong & Inappropriate & Variety \\
\hline 1 & 18 & $\mathrm{M}$ & 5 & 5 & 0 & 0 & 0 \\
\hline 2 & 19 & $\mathrm{~F}$ & 12 & 12 & 0 & 0 & 0 \\
\hline 3 & 20 & $M$ & 6 & 6 & 0 & 0 & 0 \\
\hline 4 & 20 & $M$ & 7 & 7 & 0 & 0 & 0 \\
\hline 7 & 22 & $M$ & 4 & 4 & 0 & 0 & 1 \\
\hline 8 & 20 & $\mathrm{~F}$ & 7 & 7 & 0 & 0 & 0 \\
\hline 9 & 18 & $\mathrm{~F}$ & 3 & 3 & 0 & 0 & 0 \\
\hline 10 & 21 & $\mathrm{~F}$ & 17 & 16 & 1 & 0 & 4 \\
\hline 13 & 19 & $\mathrm{~F}$ & 13 & 12 & 1 & 0 & 0 \\
\hline 14 & 19 & $\mathrm{~F}$ & 15 & 10 & 2 & 3 & 0 \\
\hline 15 & 22 & $\mathrm{~F}$ & 17 & 17 & 0 & 0 & 0 \\
\hline 16 & 22 & $\mathrm{~F}$ & 6 & 6 & 0 & 0 & 2 \\
\hline 17 & 22 & $F$ & 10 & 8 & 0 & 2 & 0 \\
\hline 18 & 21 & $M$ & 3 & 3 & 0 & 0 & 0 \\
\hline 19 & 21 & $M$ & 7 & 7 & 0 & 0 & 0 \\
\hline 20 & 21 & $M$ & 4 & 4 & 0 & 0 & 0 \\
\hline 21 & 20 & $M$ & 14 & 13 & 0 & 1 & 0 \\
\hline 22 & NR & $M$ & 24 & 23 & 0 & 1 & 7 \\
\hline 25 & 22 & $F$ & 13 & 13 & 0 & 0 & 1 \\
\hline 26 & 22 & $M$ & 18 & 17 & 0 & 1 & 3 \\
\hline 27 & 21 & $M$ & 3 & 3 & 0 & 0 & 0 \\
\hline 28 & 22 & $M$ & 13 & 13 & 0 & 0 & 3 \\
\hline 31 & 22 & $M$ & 8 & 8 & 0 & 0 & 0 \\
\hline 32 & 22 & $\mathrm{~F}$ & 8 & 8 & 0 & 0 & 0 \\
\hline 35 & 21 & $M$ & 8 & 8 & 0 & 0 & 0 \\
\hline 36 & 21 & $\mathrm{~F}$ & 7 & 7 & 0 & 0 & 0 \\
\hline 39 & 22 & $M$ & 5 & 5 & 0 & 0 & 0 \\
\hline 40 & 21 & $\mathrm{~F}$ & 10 & 10 & 0 & 0 & 1 \\
\hline 41 & 20 & $\bar{F}$ & 10 & 10 & 0 & 0 & 1 \\
\hline 42 & 22 & $M$ & 11 & 11 & 0 & 0 & 3 \\
\hline 44 & NR & $M$ & 4 & 4 & 0 & 0 & 0 \\
\hline \multirow{2}{*}{\multicolumn{3}{|c|}{$\begin{array}{r}\text { Total } \\
\text { Mean }(n=31)\end{array}$}} & 292 & 280 & 4 & 8 & 26 \\
\hline & & & 9.4 & 9.0 & \multicolumn{2}{|c|}{0.4} & 0.8 \\
\hline \multicolumn{3}{|c|}{ \# unique plants listed } & 60 & 51 & \multicolumn{2}{|c|}{9} & \\
\hline
\end{tabular}


Appendix 1b. Number of locally growing trees freelisted by by South Carolina, U.S.A. college student informants. Not recorded (NR).

\begin{tabular}{|c|c|c|c|c|c|c|c|}
\hline Informant & Age & Sex & Total Number & Correct & Wrong & Inappropriate & Species $^{\circ}$ \\
\hline 1 & 18 & $\mathrm{M}$ & 5 & 5 & 0 & 0 & 1 \\
\hline 2 & 19 & $\mathrm{~F}$ & 9 & 6 & 1 & 2 & 2 \\
\hline 3 & 20 & $\mathrm{M}$ & 10 & 9 & 1 & 0 & 3 \\
\hline 4 & 20 & $\mathrm{M}$ & 6 & 6 & 0 & 0 & 1 \\
\hline 7 & 22 & $\mathrm{M}$ & 8 & 7 & 0 & 1 & 3 \\
\hline 8 & 20 & $\mathrm{~F}$ & 11 & 10 & 0 & 1 & 3 \\
\hline 9 & 18 & $F$ & 5 & 5 & 0 & 0 & 1 \\
\hline 10 & 21 & $\mathrm{~F}$ & 27 & 25 & 1 & 1 & 18 \\
\hline 13 & 19 & $F$ & 6 & 6 & 0 & 0 & 1 \\
\hline 14 & 19 & $\mathrm{~F}$ & 14 & 14 & 0 & 0 & 11 \\
\hline 15 & 22 & $\mathrm{~F}$ & 8 & 7 & 1 & 0 & 3 \\
\hline 16 & 22 & $\mathrm{~F}$ & 5 & 5 & 0 & 0 & 1 \\
\hline 17 & 22 & $\mathrm{~F}$ & 18 & 17 & 0 & 1 & 4 \\
\hline 18 & 21 & $M$ & 6 & 6 & 0 & 0 & 1 \\
\hline 19 & 21 & $M$ & 4 & 3 & 1 & 0 & 0 \\
\hline 20 & 21 & $M$ & 3 & 3 & 0 & 0 & 0 \\
\hline 21 & 20 & $M$ & 11 & 8 & 3 & 0 & 1 \\
\hline 22 & NR & $M$ & 10 & 10 & 0 & 0 & 5 \\
\hline 25 & 22 & $\mathrm{~F}$ & 8 & 8 & 0 & 0 & 0 \\
\hline 26 & 22 & $M$ & 23 & 21 & 0 & 2 & 13 \\
\hline 27 & 21 & $M$ & 3 & 3 & 0 & 0 & 1 \\
\hline 28 & 22 & $M$ & 12 & 9 & 1 & 2 & 6 \\
\hline 31 & 22 & $\mathrm{M}$ & 16 & 9 & 4 & 3 & 3 \\
\hline 32 & 22 & $\mathrm{~F}$ & 12 & 10 & 1 & 1 & 5 \\
\hline 35 & 21 & $M$ & 3 & 2 & 0 & 1 & 0 \\
\hline 36 & 21 & $\mathrm{~F}$ & 8 & 7 & 0 & 1 & 0 \\
\hline 39 & 22 & $M$ & 11 & 10 & 1 & 0 & 3 \\
\hline 40 & 21 & $\mathrm{~F}$ & 14 & 12 & 1 & 1 & 8 \\
\hline 41 & 20 & $F$ & 10 & 8 & 0 & 2 & 5 \\
\hline 42 & 22 & $M$ & 6 & 6 & 0 & 0 & 1 \\
\hline 44 & NR & $M$ & 4 & 4 & 0 & 0 & 1 \\
\hline \multicolumn{3}{|c|}{ Total } & 296 & 261 & 16 & 19 & 105 \\
\hline \multicolumn{3}{|c|}{ Mean $(n=31)$} & 9.5 & 8.4 & \multicolumn{2}{|c|}{1.1} & 3.4 \\
\hline \multicolumn{3}{|c|}{ \# unique plants listed } & 75 & 55 & \multicolumn{2}{|c|}{20} & \\
\hline
\end{tabular}

a. Count of species includes correct and inappropriate, but not wrong answers. 


\section{in South Carolina, U.S.A.}

Appendix 1c. Number of local garden flowers (non/shrub or tree) freelisted by by South Carolina, U.S.A. college student informants. Not recorded (NR).

\begin{tabular}{|c|c|c|c|c|c|c|}
\hline Informant & Age & Sex & Total Number & Correct & Wrong & Inappropriate \\
\hline 1 & 18 & M & 4 & 4 & 0 & 0 \\
\hline 2 & 19 & $\mathrm{~F}$ & 7 & 6 & 0 & 1 \\
\hline 3 & 20 & M & 6 & 6 & 0 & 0 \\
\hline 4 & 20 & M & 7 & 5 & 1 & 1 \\
\hline 7 & 22 & M & 3 & 2 & 0 & 1 \\
\hline 8 & 20 & $\mathrm{~F}$ & 9 & 7 & 0 & 2 \\
\hline 9 & 18 & $\mathrm{~F}$ & 3 & 3 & 0 & 0 \\
\hline 10 & 21 & $\mathrm{~F}$ & 23 & 16 & 1 & 6 \\
\hline 13 & 19 & $\mathrm{~F}$ & 13 & 10 & 1 & 2 \\
\hline 14 & 19 & $\mathrm{~F}$ & 6 & 4 & 0 & 2 \\
\hline 15 & 22 & $\mathrm{~F}$ & 4 & 4 & 0 & 0 \\
\hline 16 & 22 & $\mathrm{~F}$ & 4 & 4 & 0 & 0 \\
\hline 17 & 22 & $\mathrm{~F}$ & 11 & 11 & 0 & 0 \\
\hline 18 & 21 & $\mathrm{M}$ & 2 & 1 & 0 & 1 \\
\hline 19 & 21 & $\mathrm{M}$ & 1 & 1 & 0 & 0 \\
\hline 20 & 21 & $\mathrm{M}$ & 2 & 2 & 0 & 0 \\
\hline 21 & 20 & $M$ & 3 & 3 & 0 & 0 \\
\hline 22 & NR & $\mathrm{M}$ & 3 & 1 & 2 & 0 \\
\hline 25 & 22 & $\mathrm{~F}$ & 14 & 12 & 0 & 2 \\
\hline 26 & 22 & $\mathrm{M}$ & NR & NR & NR & NR \\
\hline 27 & 21 & $\mathrm{M}$ & 3 & 3 & 0 & 0 \\
\hline 28 & 22 & $\mathrm{M}$ & 6 & 5 & 0 & 1 \\
\hline 31 & 22 & $\mathrm{M}$ & 7 & 4 & 1 & 2 \\
\hline 32 & 22 & $\mathrm{~F}$ & 9 & 9 & 0 & 0 \\
\hline 35 & 21 & $\mathrm{M}$ & 3 & 3 & 0 & 0 \\
\hline 36 & 21 & $\mathrm{~F}$ & 7 & 5 & 0 & 2 \\
\hline 39 & 22 & $\mathrm{M}$ & 8 & 7 & 0 & 1 \\
\hline 40 & 21 & $\mathrm{~F}$ & 10 & 9 & 0 & 1 \\
\hline 41 & 20 & $\mathrm{~F}$ & 10 & 9 & 0 & 1 \\
\hline 42 & 22 & $\mathrm{M}$ & 7 & 4 & 1 & 2 \\
\hline 44 & NR & $M$ & 3 & 3 & 0 & 0 \\
\hline \multicolumn{3}{|r|}{ Total } & 198 & 163 & 7 & 28 \\
\hline \multicolumn{3}{|c|}{ Mean $(n=30)$} & 6.6 & 5.4 & \multicolumn{2}{|c|}{1.2} \\
\hline \multicolumn{3}{|c|}{ \# unique plants listed } & 62 & 45 & \multicolumn{2}{|c|}{17} \\
\hline
\end{tabular}


Appendix 1d. Number of local wildflowers/weeds freelisted by by South Carolina, U.S.A. college student informants. Not recorded (NR).

\begin{tabular}{|c|c|c|c|c|c|c|}
\hline Informant & Age & Sex & Total Number & Correct & Wrong & Inappropriate \\
\hline 1 & 18 & $\mathrm{M}$ & NR & NR & NR & NR \\
\hline 2 & 19 & $\mathrm{~F}$ & NR & NR & NR & NR \\
\hline 3 & 20 & $M$ & 3 & 1 & 1 & 1 \\
\hline 4 & 20 & $M$ & 4 & 4 & 0 & 0 \\
\hline 7 & 22 & $M$ & 1 & 1 & 0 & 0 \\
\hline 8 & 20 & $\mathrm{~F}$ & 1 & 1 & 0 & 0 \\
\hline 9 & 18 & $\mathrm{~F}$ & 1 & 1 & 0 & 0 \\
\hline 10 & 21 & $\mathrm{~F}$ & 4 & 4 & 0 & 0 \\
\hline 13 & 19 & $\mathrm{~F}$ & 3 & 1 & 2 & 0 \\
\hline 14 & 19 & $\mathrm{~F}$ & 3 & 1 & 0 & 2 \\
\hline 15 & 22 & $\mathrm{~F}$ & 1 & 1 & 0 & 0 \\
\hline 16 & 22 & $\mathrm{~F}$ & 2 & 2 & 0 & 0 \\
\hline 17 & 22 & $\mathrm{~F}$ & 1 & 1 & 0 & 0 \\
\hline 18 & 21 & $\mathrm{M}$ & 2 & 1 & 0 & 1 \\
\hline 19 & 21 & $M$ & 3 & 1 & 1 & 1 \\
\hline 20 & 21 & $M$ & 2 & 0 & 1 & 1 \\
\hline 21 & 20 & $M$ & 3 & 3 & 0 & 0 \\
\hline 22 & NR & $\mathrm{M}$ & 3 & 3 & 0 & 0 \\
\hline 25 & 22 & $\mathrm{~F}$ & 5 & 2 & 1 & 2 \\
\hline 26 & 22 & $M$ & 6 & 3 & 1 & 2 \\
\hline 27 & 21 & $M$ & 1 & 1 & 0 & 0 \\
\hline 28 & 22 & $M$ & 2 & 2 & 0 & 0 \\
\hline 31 & 22 & $M$ & 2 & 1 & 1 & 0 \\
\hline 32 & 22 & $\mathrm{~F}$ & 5 & 2 & 0 & 3 \\
\hline 35 & 21 & $\mathrm{M}$ & 2 & 1 & 0 & 1 \\
\hline 36 & 21 & $\mathrm{~F}$ & 2 & 2 & 0 & 0 \\
\hline 39 & 22 & $M$ & 6 & 3 & 1 & 2 \\
\hline 40 & 21 & $\mathrm{~F}$ & 4 & 2 & 0 & 2 \\
\hline 41 & 20 & $F$ & 1 & 1 & 0 & 0 \\
\hline 42 & 22 & $M$ & 3 & 2 & 1 & 0 \\
\hline 44 & NR & $M$ & NR & NR & NR & NR \\
\hline \multicolumn{3}{|c|}{ Total } & 76 & 48 & 10 & 18 \\
\hline \multicolumn{3}{|c|}{ Mean $(n=28)$} & 2.7 & 1.7 & \multicolumn{2}{|c|}{1.0} \\
\hline \multicolumn{3}{|c|}{ \# unique plants listed } & 32 & 18 & \multicolumn{2}{|c|}{14} \\
\hline
\end{tabular}




\section{Wagner - Botanical Knowledge of a Group of College Students in South Carolina, U.S.A.}

Appendix 1e. Number of local vines freelisted by by South Carolina, U.S.A. college student informants. Not recorded (NR).

\begin{tabular}{|c|c|c|c|c|c|c|}
\hline Informant & Age & Sex & Total Number & Correct & Wrong & Inappropriate \\
\hline 1 & 18 & $M$ & 0 & 0 & 0 & 0 \\
\hline 2 & 19 & $\mathrm{~F}$ & 1 & 0 & 1 & 0 \\
\hline 3 & 20 & M & 5 & 3 & 0 & 2 \\
\hline 4 & 20 & $M$ & 5 & 3 & 2 & 0 \\
\hline 7 & 22 & $M$ & 2 & 2 & 0 & 0 \\
\hline 8 & 20 & $\mathrm{~F}$ & 3 & 3 & 0 & 0 \\
\hline 9 & 18 & $\mathrm{~F}$ & 0 & 0 & 0 & 0 \\
\hline 10 & 21 & $\mathrm{~F}$ & 7 & 4 & 3 & 0 \\
\hline 13 & 19 & $\mathrm{~F}$ & 3 & 2 & 1 & 0 \\
\hline 14 & 19 & $\mathrm{~F}$ & 2 & 2 & 0 & 0 \\
\hline 15 & 22 & $\mathrm{~F}$ & 0 & 0 & 0 & 0 \\
\hline 16 & 22 & $\mathrm{~F}$ & 3 & 2 & 1 & 0 \\
\hline 17 & 22 & $\mathrm{~F}$ & 5 & 5 & 0 & 0 \\
\hline 18 & 21 & $M$ & 2 & 2 & 0 & 0 \\
\hline 19 & 21 & $M$ & 1 & 1 & 0 & 0 \\
\hline 20 & 21 & $M$ & 1 & 1 & 0 & 0 \\
\hline 21 & 20 & $M$ & 1 & 1 & 0 & 0 \\
\hline 22 & NR & $M$ & 1 & 0 & 0 & 1 \\
\hline 25 & 22 & $\mathrm{~F}$ & 3 & 3 & 0 & 0 \\
\hline 26 & 22 & $M$ & 5 & 5 & 0 & 0 \\
\hline 27 & 21 & $M$ & 1 & 1 & 0 & 0 \\
\hline 28 & 22 & $M$ & 0 & 0 & 0 & 0 \\
\hline 31 & 22 & $M$ & 1 & 1 & 0 & 0 \\
\hline 32 & 22 & $\mathrm{~F}$ & 1 & 1 & 0 & 0 \\
\hline 35 & 21 & $M$ & 1 & 1 & 0 & 0 \\
\hline 36 & 21 & $F$ & 1 & 1 & 0 & 0 \\
\hline 39 & 22 & $M$ & 11 & 6 & 3 & 2 \\
\hline 40 & 21 & $\mathrm{~F}$ & 2 & 2 & 0 & 0 \\
\hline 41 & 20 & $\mathrm{~F}$ & 4 & 3 & 1 & 0 \\
\hline 42 & 22 & $M$ & 2 & 2 & 0 & 0 \\
\hline 44 & NR & $M$ & 2 & 2 & 0 & 0 \\
\hline \multicolumn{3}{|c|}{ Total } & 76 & 59 & 12 & 5 \\
\hline \multicolumn{3}{|c|}{ Mean $(n=31)$} & 2.5 & 1.9 & \multicolumn{2}{|c|}{0.5} \\
\hline \multicolumn{3}{|c|}{ \# unique plants listed } & 17 & 9 & \multicolumn{2}{|c|}{10} \\
\hline
\end{tabular}


Appendix 1f. Number of local grasses freelisted by South Carolina, U.S.A. college student informants. Not recorded (NR).

\begin{tabular}{|c|c|c|c|c|c|c|}
\hline Informant & Age & Sex & Total Number & Correct & Wrong & Inappropriate \\
\hline 1 & 18 & $M$ & 0 & 0 & 0 & 0 \\
\hline 2 & 19 & $\mathrm{~F}$ & 0 & 0 & 0 & 0 \\
\hline 3 & 20 & $M$ & 2 & 1 & 1 & 0 \\
\hline 4 & 20 & $M$ & 1 & 1 & 0 & 0 \\
\hline 7 & 22 & $M$ & 0 & 0 & 0 & 0 \\
\hline 8 & 20 & $\mathrm{~F}$ & 0 & 0 & 0 & 0 \\
\hline 9 & 18 & $F$ & 1 & 1 & 0 & 0 \\
\hline 10 & 21 & $\mathrm{~F}$ & 2 & 1 & 1 & 0 \\
\hline 13 & 19 & $\mathrm{~F}$ & 1 & 1 & 0 & 0 \\
\hline 14 & 19 & $\mathrm{~F}$ & 2 & 1 & 1 & 0 \\
\hline 15 & 22 & $\mathrm{~F}$ & 0 & 0 & 0 & 0 \\
\hline 16 & 22 & $\bar{F}$ & 1 & 1 & 0 & 0 \\
\hline 17 & 22 & $F$ & 2 & 2 & 0 & 0 \\
\hline 18 & 21 & $M$ & 0 & 0 & 0 & 0 \\
\hline 19 & 21 & $M$ & 2 & 0 & 2 & 0 \\
\hline 20 & 21 & $M$ & 3 & 2 & 1 & 0 \\
\hline 21 & 20 & $M$ & 4 & 4 & 0 & 0 \\
\hline 22 & NR & $M$ & 2 & 2 & 0 & 0 \\
\hline 25 & 22 & $\mathrm{~F}$ & 2 & 1 & 1 & 0 \\
\hline 26 & 22 & $\mathrm{M}$ & 9 & 7 & 2 & 0 \\
\hline 27 & 21 & $M$ & 3 & 2 & 1 & 0 \\
\hline 28 & 22 & $M$ & 3 & 2 & 1 & 0 \\
\hline 31 & 22 & $\mathrm{M}$ & 3 & 3 & 0 & 0 \\
\hline 32 & 22 & $\mathrm{~F}$ & 3 & 3 & 0 & 0 \\
\hline 35 & 21 & $M$ & 1 & 0 & 1 & 0 \\
\hline 36 & 21 & $\mathrm{~F}$ & 0 & 0 & 0 & 0 \\
\hline 39 & 22 & $M$ & 6 & 5 & 1 & 0 \\
\hline 40 & 21 & $\mathrm{~F}$ & 0 & 0 & 0 & 0 \\
\hline 41 & 20 & $\bar{F}$ & 0 & 0 & 0 & 0 \\
\hline 42 & 22 & $\mathrm{M}$ & 3 & 3 & 0 & 0 \\
\hline 44 & NR & $\mathrm{M}$ & 1 & 1 & 0 & 0 \\
\hline \multicolumn{3}{|r|}{ Total } & 57 & 44 & 13 & 0 \\
\hline \multicolumn{3}{|c|}{ Mean $(n=31)$} & 1.8 & 1.4 & \multicolumn{2}{|c|}{0.4} \\
\hline \multicolumn{3}{|c|}{ \# unique plants listed } & 24 & 12 & \multicolumn{2}{|c|}{12} \\
\hline
\end{tabular}

